\title{
2-Year Real-World Outcomes with Intravitreal Aflibercept in Neovascular Age-Related Macular Degeneration: Literature Review and Meta-analysis of Patient-Relevant Outcomes
}

\author{
Joao Carrasco (D) - Vincent Daien · Bora M. Eldem · Jelle A. Spoorendonk • \\ Jisu Yoon
}

Received: March 30, 2021 / Accepted: April 30, 2021 / Published online: June 1, 2021

(C) The Author(s) 2021

\section{ABSTRACT}

Background: The 96 weeks' assessment from the VIEW studies provided insights into the long-term efficacy of intravitreal aflibercept (IVT-AFL) in neovascular age-related macular degeneration (nAMD) and demonstrated that it was possible to maintain long-term outcomes while moving from a fixed bimonthly regimen in Year 1 to a variable dosing regimen in Year 2.

Supplementary Information The online version contains supplementary material available at https:// doi.org/10.1007/s40123-021-00350-5.

J. Carrasco $(\bowtie)$

Pharmaceuticals, Bayer Consumer Care AG, Peter Merian-Strasse 84, 4052 Basel, Switzerland e-mail: joao.carrasco@bayer.com

V. Daien

Department of Ophthalmology, Gui De Chauliac Hospital, Montpellier, France

\section{Daien}

The Save Sight Institute, Sydney Medical School, The University of Sydney, Sydney, NSW, Australia

B. M. Eldem

Faculty of Medicine, Ophthalmology Department, Hacettepe University, Ankara, Turkey

\section{J. A. Spoorendonk}

Pharmerit International, An OPEN Health

Company, Rotterdam, The Netherlands

J. Yoon

Pharmerit International, An OPEN Health

Company, Berlin, Germany
The aim of this analysis was to perform a literature review and meta-analysis assessing the use of IVT-AFL and real-world outcomes in treatment-naïve patients with nAMD treated with IVT-AFL for 2 years, as per label.

Methods: A literature review and meta-analysis were performed to provide an overview of the baseline characteristics of the population, the 2-year outcomes, the associated treatment burden, and safety.

Results: Eleven publications providing data from patients with nAMD who had treatment initiated with IVT-AFL between 2012 and 2016 were identified. The mean baseline age of patients was 78.62 years, with a baseline bestcorrected visual acuity (BCVA) of 57.73 Early Treatment Diabetic Retinopathy Study (ETDRS) letters. Patients reported a mean BCVA at 2 years of 62.55 ETDRS letters, with $47.39 \%$ of patients having a BCVA $\geq 70$ ETDRS letters. Mean gain in BCVA versus baseline was +4.49 ETDRS letters for the combined population $(+5.91$ letters for patients treated with a treatand-extend regimen). Over the 2 years of the study, patients received an average of 12.34 injections, with a reduction in injections in Year 2 versus Year 1. The qualitative assessment of the safety data suggested that no new safety signals were identified.

Conclusion: Patients treated with IVT-AFL reported significant gains in visual acuity versus baseline after 2 years. The evidence identified indicates that the visual gains achieved during 
the first year of treatment are maintained through the second year and that these were achieved with a reduction in the mean number of IVT-AFL injections administered in Year 2 of treatment.

Keywords: Age-related macular degeneration; Intravitreal aflibercept; Patient outcomes; Realworld outcomes; Treatment burden

\section{Key Summary Points}

The 96 weeks' assessment of the VIEW studies provided insights regarding the long-term efficacy of intravitreal aflibercept (IVT-AFL) in the treatment of neovascular age-related macular degeneration (nAMD) and demonstrated that it was possible to maintain long-term outcomes while moving from a fixed bimonthly regimen in Year 1 to a variable dosing regimen in Year 2 in a clinical trial setting.

Because clinical trial treatment protocols and clinical trial results may not always be replicable in real-world settings, our objective was to conduct a systematic literature review and meta-analysis of the published evidence describing 2-year outcomes in treatment-naïve patients with nAMD treated with IVT-AFL.

The aim of the analysis was to describe the characteristics of the population treated with IVT-AFL in routine clinical practice, the IVT-AFL treatment approaches used, and how key patient relevant outcomes, such as change in visual acuity (VA) evolved.

The analysis showed that, after 2 years, patients treated with IVT-AFL reported significant gains in VA versus baseline. The evidence identified shows that it was possible to achieve good long-term outcomes with IVT-AFL in clinical practice and maintain the VA gains achieved during the first year of treatment in the second year.
Patients were primarily treated using proactive treatment approaches that included fixed bimonthly regimens in Year 1 and variable dosing regimens in Year 2; as well as treat-and-extend posologies. In most cases, the injection frequency decreased significantly from Year 1 to Year 2 without compromising the patients' VA.

A qualitative assessment of the safety data reported in the literature suggests that there were no new safety signals identified during the studies and very few adverse events were identified.

\section{DIGITAL FEATURES}

This article is published with digital features, including a summary slide, to facilitate understanding of the article. To view digital features for this article go to https://doi.org/10.6084/ m9.figshare.14510706.

\section{INTRODUCTION}

Age-related macular degeneration (AMD) is a leading cause of visual impairment and blindness worldwide [1]. Most of the AMD-related blindness that occurs is associated with the neovascular (or "wet") form of AMD (nAMD) [2]. Anti-vascular endothelial growth factor (anti-VEGF) agents have been demonstrated to be efficacious and safe treatment options for managing patients with nAMD [3-6] and have changed the treatment paradigm of the disease [7]. Anti-VEGF agents are currently considered to be a preferred option for managing patients with nAMD [7] and set the benchmark for all new treatment options in nAMD. The VIEW 1 \& 2 studies assessed the efficacy and safety of intravitreal aflibercept (IVT-AFL) in nAMD and established that a regimen comprising fixedinterval treatment with IVT-AFL during the Year-1 interval was non-inferior to the monthly 
intravitreal ranibizumab regimen $[5,6]$. The short-term efficacy and safety of the bimonthly regimen with IVT-AFL was well established in the pivotal trials $[5,6]$, and the 2-year data from the VIEW studies provided the first insights into the long-term efficacy of IVT-AFL in nAMD [6], demonstrating that it was possible to maintain the visual acuity (VA) gains achieved in the first year of treatment while moving from a fixed bimonthly regimen to a modified quarterly dosing regimen [6].

The evidence from the randomized clinical trials was supplemented with real-world evidence describing the short-term effectiveness and safety of the proactive bimonthly regimen with IVT-AFL [8-12]. A study by Talks et al. [8] provided the first insight into the real-world effectiveness of IVT-AFL in treatment-naïve patients with nAMD. The implementation of a "VIEW-like" treatment regimen of three consecutive initial monthly doses followed by a bimonthly regimen helped to significantly improve patients' VA, with mean gains in VA at Week 52 being comparable to the VA gains observed in the randomized trials [8]. Comprehensive literature reviews and meta-analysis of real-world data support the findings and conclusions of the individual studies and characterize the value of the proactive bimonthly regimen with IVT-AFL in clinical practice [13-15]. Researchers, including Eleftheriadou et al. [16], have provided insights into the 2-year effectiveness of IVT-AFL in a population that was primarily treated with the fixed bimonthly treatment approach in Year 1 and with a variable dosing regimen in Year 2 of treatment. The implementation of a variable dosing regimen with IVT-AFL in Year 2 reduced the injection frequency without compromising the patient's VA gains [16]. Evidence describing the 2-year use and 2-year effectiveness of IVTAFL in nAMD has increased significantly over the past few years, and there is value in performing a review of 2-year outcomes in treatment-naïve patients with nAMD. The aim of this analysis was to conduct a literature review and meta-analysis of the published evidence describing 2-year outcomes in treatment-naïve patients with nAMD who were treated with IVTAFL in clinical practice.

\section{METHODS}

A literature review and meta-analysis were performed to provide a comprehensive overview of the population treated with IVT-AFL, including baseline characteristics, 2-year outcomes, associated treatment burden, and overall safety.

This article is based on previously conducted studies and does not contain any new studies with human participants or animals performed by any of the authors.

\section{Literature Review}

A literature search identified publications of observational studies describing the 2-year use of IVT-AFL in treatment-naïve patients with nAMD. The search strategy that was the basis for the literature review included a variety of synonyms for nAMD and IVT-AFL (Electronic Supplementary Material [ESM] Digital Content 1). The search was conducted in the MEDLINE ${ }^{\circledR}$ database using ProQuest. The search string considered Medical Subject Headings (MeSH) terms and search syntax aiming to search in the title or abstract and free text, using quotation marks and Boolean operators. The search date for the literature was 8 July 2019 and studies published earlier were included.

\section{Study Selection and Data Extraction}

The literature review targeted observational studies with a prospective or retrospective study design describing the use of IVT-AFL in treatment-naïve patients with nAMD. Studies had to report a minimum follow-up period of 2 years and had to enroll at least 40 patients/eyes (see ESM Digital Content 1 for full inclusion and exclusion criteria). Studies were selected based on population, intervention, comparator, outcomes, and study design (PICOS) criteria [17]. Title, abstract, and full-text screening were performed by one reviewer. Inclusion and exclusion per stage was reported according to a Preferred Reporting Items for Systematic Reviews and Meta-Analyses (PRISMA) flow chart [18]. The data extraction template was developed considering various aspects of the 
Meta-Analyses and Systematic Reviews of Observational Studies (MOOSE) guidelines [19]. The authors referred to the PRISMA [18] and MOOSE [19] guidelines for guidance and support at different stages of the analysis but did not adhere to all of the recommendations and activities described in the guidelines. Study duplicates were also removed (e.g., if there was more than one publication describing the same population or overlapping populations, only one was selected).

\section{Variables of Interest and Statistical Analyses}

The meta-analysis used aggregate data from the studies identified in the literature review and followed a similar approach as that of a previous meta-analysis assessing real-world effectiveness of anti-VEGF [20]. Variables of interest included patient baseline characteristics (defined as baseline best-corrected VA [BCVA] and age at baseline), 2-year outcomes (defined as BCVA change from baseline to Year 2, percentage of patients achieving a VA $\geq 70$ Early Treatment Diabetic Retinopathy Study [ETDRS] letters at Year 2, and VA at Year 2), treatment burden (defined as mean number of injections over the 2 years of treatment), and safety (any drugrelated event reported in the publications). If sufficient data were available, subgroup analysis was conducted, considering study design (prospective non-interventional vs. retrospective non-interventional), country/region, and treatment approach (proactive bimonthly followed by variable dosing regimen vs. other). To account for possible heterogeneity in outcome between studies, a random-effects model in addition to a fixed-effects model was used to produce estimates for all variables of interest. When necessary, data from individual studies were converted to the units of interest (e.g., ETDRS letters is the unit of interest for measuring the change in VA; ESM Digital Content 2 ). When studies did not report the standard errors necessary for the meta-analysis, these values were imputed via the multivariate imputation by chained equations (MICE) algorithm [21]. Multiple imputation was used; as such, the confidence interval (CI) considers the uncertainty of imputation. Heterogeneity was measured using the $I^{2}$ statistic [22]. The metaanalyses were performed using the metafor package [23] and the MICE algorithm with the software environment R (R Foundation for Statistical Computing, Vienna, Austria). Outcomes are reported as means (with 95\% CI).

\section{Meta-Regression}

To assess the potential heterogeneity associated with pooled estimates from the meta-analysis, a meta-regression was conducted for each aforementioned outcome using region and study design as covariates. Additionally, meta-regressions were assessed if there were associations between 2-year outcomes with IVT-AFL (VA change from baseline to Year 2) and other covariates: region; VA at baseline; age at baseline; central retinal thickness (CRT) at baseline; mean number of injections in Year 1; and mean number of injections over the 2 years. The meta-regression investigated each of these covariates separately per regression.

\section{RESULTS}

\section{Literature Review}

The results of the literature review are presented in Fig. 1. A total of 823 publications were identified in the initial search. After screening for title and abstract, 63 publications were eligible for full-text review. After a full-text review, 17 publications were selected for data extraction. During the data extraction, six of the 17 publications were excluded (due to $<40$ patients, overlapping populations, and lack of data availability), leaving 11 publications [24-34] (Table 1). These 11 publications report realworld data for patients who initiated treatment with IVT-AFL between 2012 and 2016 [25-34]. Study sizes ranged from 40 patients/eyes [32] to 2506 patients/eyes [27], with some studies reporting subpopulations $[27,30,31]$. The publications described outcomes achieved following a fixed bimonthly (every 8 weeks) 


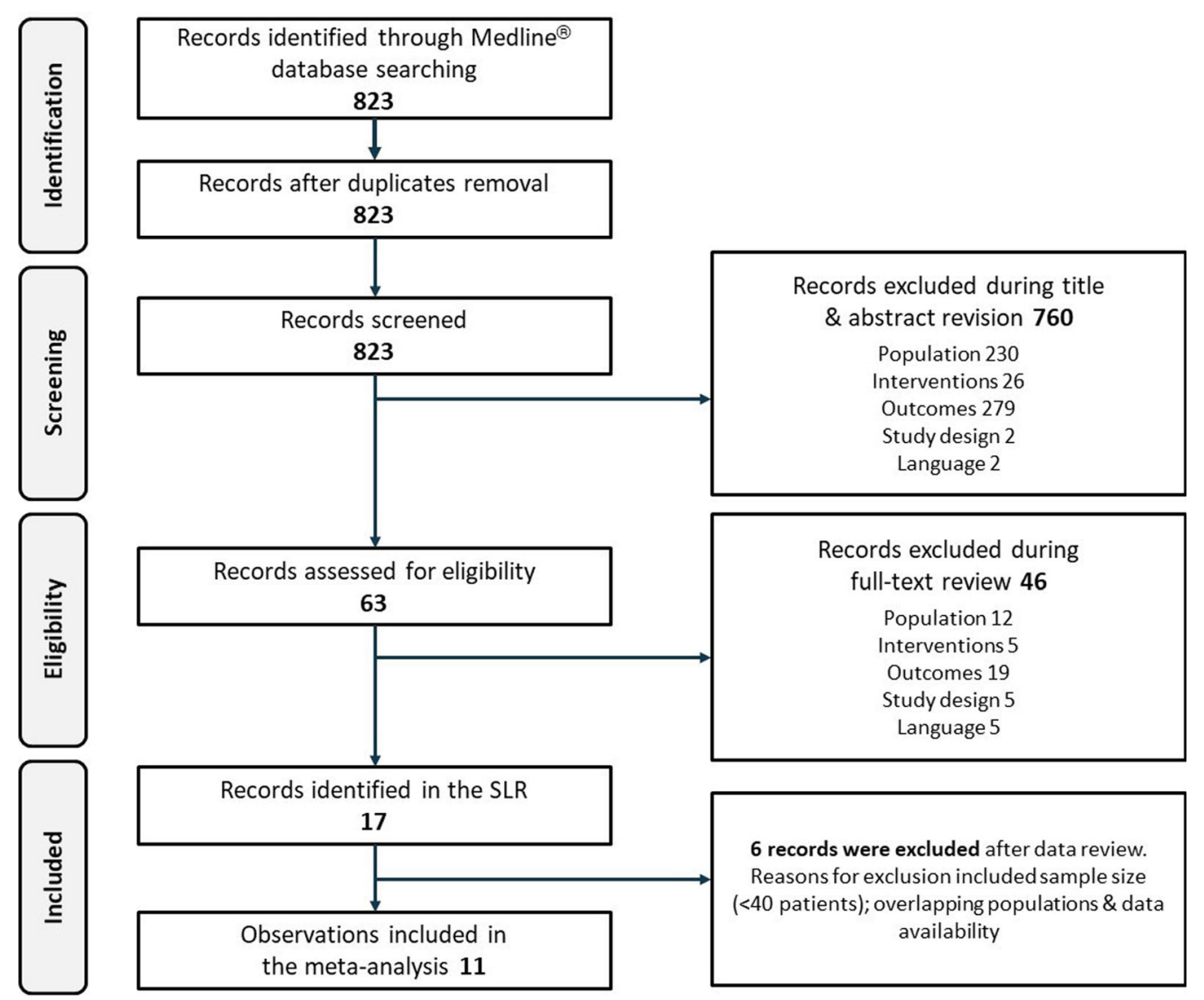

Fig. 1 PRISMA flow diagram. PRISMA Preferred Reporting Items for Systematic Reviews and Meta-Analyses, SLR systematic literature review

regimen in Year 1 and a variable regimen in Year 2 (2q8), using treat-and-extend (T\&E) and pro re nata (PRN; as needed) regimens (Table 1).

\section{Patients' Baseline Characteristics}

Patients' baseline age ranged between 75.1 years $[30]$ and $>90$ years $[27,33]$. The pooled analysis estimated a mean age of 78.62 years $(95 \% \mathrm{CI}$ 76.18-81.07; $\left.I^{2} 96.55 \%\right)$ for the combined population (random-effects estimate; Table 2). No clinically significant differences in baseline age were observed between the combined population and the subgroup analysis (random-effects estimate; Table 2). BCVA ranged between 52.5 ETDRS letters [27] and 75.0 ETDRS letters [30], with the majority of the studies reporting patients with a mean baseline VA of $<60.00$ ETDRS letters $[24,25,27,28,31-34]$. The pooled analysis estimated a mean baseline BCVA of 57.73 ETDRS letters (95\% CI 54.23-61.24; $\left.I^{2} 93.52 \%\right)$ for the combined population (Table 2). When compared with the combined population, patients included in studies that implemented T\&E regimens had a higher mean baseline BCVA of 60.21 ETDRS letters (95\% CI 54.87-65.56; $I^{2}$ 82.16; randomeffects estimate; Table 2). The evidence identified in the literature review only allowed for a subgroup analysis assessing the characteristics of the European-based studies versus the combined population. No clinically significant differences for the baseline BCVA were identified between the combined population and the population included in the European studies (Table 2). Due to the limited number of prospective studies [30], the analysis focusing on addressing prospective or retrospective 
Table 1 Summary of studies identified in the literature review and included in the meta-analysis

\begin{tabular}{|c|c|c|c|c|c|c|c|c|}
\hline Study & $\begin{array}{l}\text { Patients/ } \\
\text { eyes }(N)\end{array}$ & $\begin{array}{l}\text { Baseline } \\
\text { age } \\
\text { (years) }\end{array}$ & $\begin{array}{l}\text { Baseline } \\
\text { BCVA } \\
\text { (ETDRS } \\
\text { letters) }\end{array}$ & $\begin{array}{l}\text { Treatment } \\
\text { regimen }^{\mathrm{a}}\end{array}$ & $\begin{array}{l}\text { IVT-AFL } \\
\text { injections } \\
\text { (at } \\
2 \text { years) }\end{array}$ & $\begin{array}{l}\text { BCVA } \\
2 \text { years } \\
\text { (ETDRS } \\
\text { letters) }\end{array}$ & $\begin{array}{l}\text { Patients with } \\
\text { BCVA } \geq 70 \\
\text { ETDRS } \\
\text { letters }(\%)\end{array}$ & $\begin{array}{l}\Delta \text { BCVA } \\
\text { vs. baseline } \\
\text { (ETDRS } \\
\text { letters) }\end{array}$ \\
\hline $\begin{array}{c}\text { Almuhtaseb } \\
{[24]^{\mathrm{b}}}\end{array}$ & 1083 & 82.00 & 56.30 & $2 \mathrm{q} 8 / \mathrm{PRN}$ & - & 59.10 & - & +2.80 \\
\hline $\begin{array}{c}\text { Augsburger } \\
{[25]^{c}}\end{array}$ & 419 & 79.80 & 55.00 & $\mathrm{~T} \& \mathrm{E}$ & - & - & - & - \\
\hline $\begin{array}{l}\text { Barthelmes } \\
{[26]}\end{array}$ & 123 & 77.20 & 61.40 & $\mathrm{~T} \& \mathrm{E}$ & 13.60 & 67.40 & $58.00 \%$ & +6.00 \\
\hline \multirow{2}{*}{$\begin{array}{c}\text { Chatziralli } \\
{[27]^{\mathrm{d}}}\end{array}$} & 2506 & $<90$ & 56.30 & $2 \mathrm{q} 8$ & - & 58.40 & - & +2.10 \\
\hline & 228 & $>90$ & 52.80 & $2 \mathrm{q} 8$ & - & 52.00 & - & -0.80 \\
\hline $\begin{array}{l}\text { Eleftheriadou } \\
\quad[28]\end{array}$ & 131 & 80.60 & 54.40 & $2 \mathrm{q} 8$ & 12.00 & 60.80 & $38.90 \%$ & +6.40 \\
\hline Garweg [29] & 106 & 79.00 & 62.40 & $\mathrm{~T} \& \mathrm{E}$ & 11.70 & 62.50 & - & +0.50 \\
\hline \multirow{2}{*}{$\begin{array}{l}\text { Matsumoto } \\
{[30]^{\mathrm{d}}}\end{array}$} & $44^{\mathrm{e}}$ & 71.50 & 72.00 & $\mathrm{~T} \& \mathrm{E}$ & 12.39 & 78.00 & - & +6.00 \\
\hline & $18^{\mathrm{e}}$ & 75.70 & 53.50 & $\mathrm{~T} \& \mathrm{E}$ & 14.12 & 62.50 & - & +9.00 \\
\hline \multirow{2}{*}{$\begin{array}{c}\text { Mekjavić } \\
{[31]^{\mathrm{d}}}\end{array}$} & 105 & 77.30 & 57.90 & $\mathrm{~T} \& \mathrm{E}$ & 14.50 & 64.80 & $43.5 \%$ & +7.00 \\
\hline & 33 & 76.30 & 62.40 & $2 \mathrm{q} 8 / \mathrm{PRN}$ & 10.30 & 63.20 & $51.50 \%$ & +1.20 \\
\hline Siempsis [32] & 40 & - & 52.50 & $2 \mathrm{q} 8$ & 9.40 & 56.70 & - & +4.20 \\
\hline Subhi [33] & 49 & - & 50.00 & PRN & 6.70 & - & - & +3.40 \\
\hline Traine [34] & 173 & 79.90 & 59.80 & $\mathrm{~T} \& \mathrm{E}$ & 11.10 & 65.50 & - & +5.70 \\
\hline
\end{tabular}

$2 q 8$ fixed bimonthly (every 8 weeks) in Year 1 and variable in Year 2, BCVA best-corrected visual acuity, ETDRS Early Treatment Diabetic Retinopathy Study, IVT-AFL intravitreal aflibercept, $P R N$ pro re nata (as needed), TङE treat and extend

${ }^{\text {a }}$ As indicated in the original publication

b The mean number of injections in Year 1 was not reported, only mean number in Year 2

c Mean injection and BCVA were not reported at 2 years

${ }^{\mathrm{d}}$ For the pooled analysis, the weighted mean was considered

e Population with typical age-related macular degeneration (AMD) with classic choroidal neovascularization and population with typical AMD and occult choroidal neovascularization

studies had limited validity; therefore, this is not reported. The previously mentioned limitations for the subgroup analysis assessing potential differences in the populations based on study design and region were also present for the effectiveness and treatment burden analysis.

\section{2-Year Outcomes with IVT-AFL}

The BCVA at 2 years varied between 52.0 ETDRS letters [27] and 78.0 ETDRS letters [30] (Table 1). The pooled analysis estimated a mean BCVA of 62.55 ETDRS letters (95\% CI 58.06-67.05) for the combined population at 2 years (randomeffects estimate; Table 2). When compared with the combined population, patients included in 
Table 2 Pooled estimates for patient baseline characteristics, long-term (2-year) outcomes, and treatment burden with IVTAFL

\begin{tabular}{|c|c|c|c|c|c|}
\hline Pooled estimates & $\begin{array}{l}\text { Fixed-effects estimate } \\
(95 \% \mathrm{CI})\end{array}$ & $\begin{array}{l}\text { Random-effects estimate } \\
(95 \% \mathrm{CI})\end{array}$ & $\begin{array}{l}I^{2} \\
(\%)\end{array}$ & $\begin{array}{l}\text { Moderator } \\
R^{2}\end{array}$ & $N$ \\
\hline Baseline age, overall (years) & $80.36(79.81-80.91)$ & $78.62(76.18-81.07)$ & 96.55 & & 8 \\
\hline Baseline age-region & $79.30(78.16-80.44)$ & $78.99(76.10-81.89)$ & 81.49 & 65.22 & 4 \\
\hline Baseline age $-\mathrm{T} \& \mathrm{E}$ studies & $78.62(77.66-79.58)$ & $77.44(73.33-81.56)$ & 95.65 & - & 3 \\
\hline $\begin{array}{l}\text { Baseline BCVA, overall (ETDRS } \\
\text { letters) }\end{array}$ & $56.58(55.99-57.18)$ & $57.73(54.23-61.24)$ & 93.52 & & 10 \\
\hline Baseline BCVA-region & $58.59(56.37-60.81)$ & $57.41(50.53-64.29)$ & 89.92 & 40.08 & 5 \\
\hline Baseline BCVA-T\&E studies & $59.90(57.77-62.04)$ & $60.21(54.87-65.56)$ & 82.16 & - & 5 \\
\hline VA after 2 years (ETDRS letters) & $60.95(60.01-61.89)$ & $62.55(58.06-67.05)$ & 93.93 & & 9 \\
\hline VA after 2 years-region & $62.97(58.87-67.06)$ & $61.71(50.47-72.95)$ & 90.58 & 52.35 & 4 \\
\hline VA after 2 years-T\&E studies & $66.34(62.95-69.72)$ & $67.19(59.48-74.55)$ & 76.89 & - & 4 \\
\hline $\begin{array}{l}\text { Change in VA vs. baseline (ETDRS } \\
\text { letters) }\end{array}$ & $2.70(0.55-4.85)$ & $4.49(2.47-6.50)$ & 77.12 & & 9 \\
\hline Change in VA-region & $4.57(-2.31$ to 11.46$)$ & $4.10(-3.19$ to 11.39$)$ & 68.62 & $0.11^{\mathrm{c}}$ & 4 \\
\hline Change in VA-T\&E studies & $5.91(3.21-8.57)$ & $5.91(3.25-8.57)$ & 0.00 & - & 4 \\
\hline $\begin{array}{l}\text { Patients with VA }>70 \text { ETDRS } \\
\text { letters }(\%)^{\mathrm{a}}\end{array}$ & $47.42(45.64-49.20)$ & $47.39(-1.16$ to 95.95$)$ & 99.87 & & 3 \\
\hline $\begin{array}{l}\text { No. IVT-AFL injections after } 2 \\
\text { years }{ }^{b}\end{array}$ & $12.59(12.11-13.07)$ & $12.34(10.47-14.22)$ & 94.37 & & 6 \\
\hline $\begin{array}{l}\text { IVT-AFL injections-T\&E } \\
\text { studies }\end{array}$ & $13.59(11.76-15.42)$ & $13.59(11.76-15.45)$ & 0.00 & - & 3 \\
\hline
\end{tabular}

$C I$ Confidence interval, $V A$ visual acuity

a Insufficient data points to provide pooled estimate for region, retrospective studies, or T\&E studies independently

${ }^{b}$ Insufficient data points to provide pooled estimate for region independently

${ }^{c}$ Estimated from a meta-regression with intercept, UK, and Europe as covariates ( $N$ same as the overall analysis)

studies that implemented T\&E regimens reported a higher mean BCVA at 2 years of 67.19 ETDRS letters (95\% CI 59.44-74.55, I $I^{2}$ 76.89; random-effects estimate; Table 2). The percentage of patients with BCVA $\geq 70$ ETDRS letters at 2 years varied between $38.90 \%$ [28] and $58.00 \%$ [31], with all studies reporting an increase in the number of patients with BCVA $\geq 70$ ETDRS letters versus baseline. The pooled analysis estimated a mean percentage of patients with
BCVA $\geq 70$ ETDRS letters at 2 years of $47.39 \%$ (95\% CI -1.16 to 95.95 ; $I^{2} 99.87 \%$; randomeffects estimate; Table 2). No clinically significant differences were identified between the combined population and the population included in the European studies for the mean gain in BCVA at Year 2 (Table 2).

Mean gains in VA after 2 years of IVT-AFL ranged from -0.80 ETDRS letters [27] to +9.00 ETDRS letters [30], with four studies reporting 
mean gains of $\geq 6$ ETDRS letters [26, 28, 30, 31] (Table 1). The pooled analysis estimated a mean change in BCVA versus baseline of 4.49 ETDRS letters (95\% CI 2.47-6.50; $I^{2} 77.12 \%$; randomeffects estimate; Table 2). The 2-year VA gains for the individual studies and the combined population are presented in Fig. 2. When compared with the combined population, patients included in studies that implemented T\&E regimens reported a higher gain in VA at 2 years of +5.91 letters $\left(95 \%\right.$ CI 3.25-8.57, $\left.I^{2}-0.00\right)$ (random-effects estimate; Table 2).

\section{Treatment Burden with IVT-AFL}

The mean number of injections with IVT-AFL over 2 years varied depending on the treatment regimen (Table 1 ). Patients on a PRN regimen received a mean of 6.7 injections over the 2 years [33] and patients on 2q8 received between 9.9 and 12.0 injections [32, 34]. Injection frequency ranged between 10.5 [29] and 13.8 [30] for the patients on T\&E regimens. The analysis of the individual studies indicates that the injection frequency decreased from Year 1 (between 7.2 injections [28] and 8.4 injections [31]) to Year 2 (between 2.5 injections and 6.1 injections [31]) in patients treated following $2 \mathrm{q} 8$ or T\&E regimens. The pooled analysis estimated that patients received a mean of 12.34 injections (95\% CI 10.47-14.22; $I^{2}$ 94.37\%; random-effects estimate; Table 2) over 2 years. When compared with the combined population, patients included in studies that implemented T\&E regimens received a higher mean of 13.59 injections (95\% CI 11.76-15.45, $I^{2} 0.00$; random-effects estimate; Table 2 ).

\section{2-Year Safety}

When assessing 2-year safety, several limitations were identified. Few of the publications identified in the literature review included a safety assessment and those that included safety data primarily only provided a qualitative description (Table 3). Considering this lack of information, it was not possible to complete a formal meta-analysis on safety and provide pooled estimates. The assessment of the 2-year safety was therefore primarily based on the qualitative assessments made by the original study teams (Table 3).

\section{Meta-regression Analysis}

The meta-regression did not identify any statistically significant association between the variables analyzed (region, baseline BCVA and age, baseline CRT, mean number of injections over the 2 years, and mean number of injections in the first year of treatment) and 2-year outcomes with IVT-AFL (Table 4). There was a

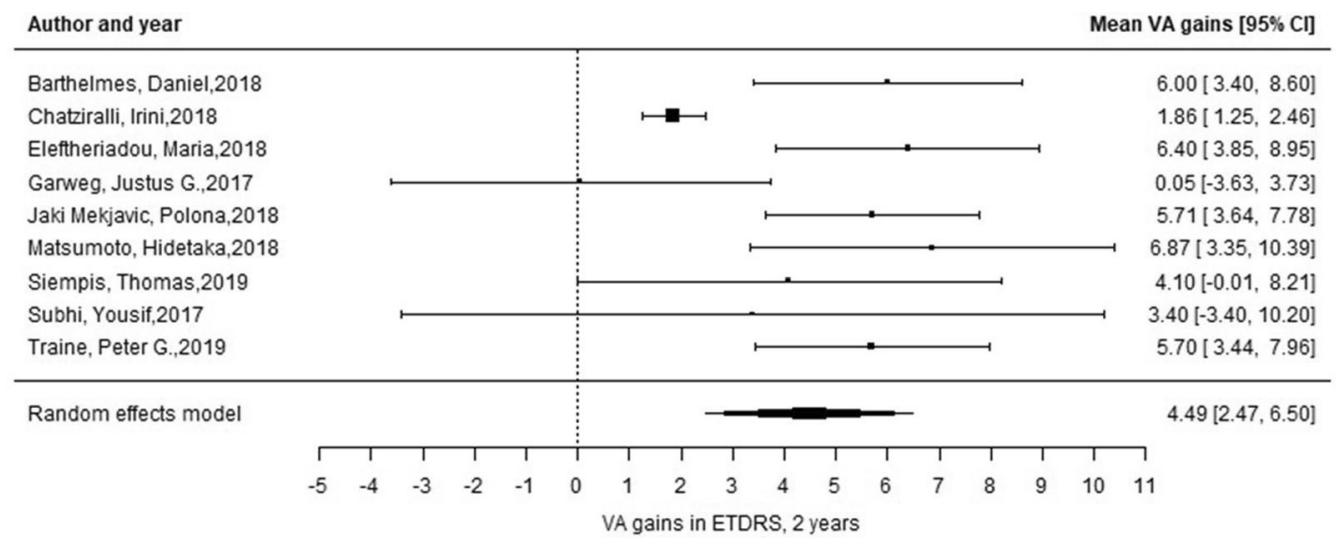

Fig. 2 Forest plot describing 2-year outcomes with IVTAFL in nAMD (mean VA gains at Year 2; 95\% CI). CI Confidence interval, ETDRS Early Treatment Diabetic
Retinopathy Study, IVT-AFL intravitreal aflibercept, $n A M D$ neovascular age-related macular degeneration, $V A$ visual acuity 
Table 3 Qualitative description of the 2-year safety with IVT-AFL in treatment-naive patients with neovascular AMD

\begin{tabular}{|c|c|}
\hline Study & Safety assessment \\
\hline $\begin{array}{l}\text { Almuhtaseb } \\
\quad[24]\end{array}$ & No safety assessment included \\
\hline $\begin{array}{l}\text { Augsburger } \\
\text { [25] }\end{array}$ & No safety assessment included \\
\hline $\begin{array}{l}\text { Barthelmes } \\
\text { [26] }\end{array}$ & $\begin{array}{l}\text { "Over the course of the study period, } 10 \text { adverse events resulting from } 2415 \text { injections were observed in all } \\
\text { eyes, including non-completers and switchers: } 2 \text { eyes had hemorrhage reducing best-corrected visual } \\
\text { acuity by } 0.15 \text { letters, and } 3 \text { eyes had retinal pigment epithelium tears." }\end{array}$ \\
\hline Chatziralli [27] & No safety assessment included \\
\hline $\begin{array}{l}\text { Eleftheriadou } \\
\text { [28] }\end{array}$ & No safety assessment included \\
\hline Garweg [29] & No safety assessment included \\
\hline $\begin{array}{l}\text { Matsumoto } \\
\quad[30]\end{array}$ & $\begin{array}{l}\text { "None of our subjects experienced severe adverse events, such as cerebral infarction, myocardial infarction, } \\
\text { infectious endophthalmitis, and rhegmatogenous retinal detachment." }\end{array}$ \\
\hline Mekjavić [31] & $\begin{array}{l}\text { "The following ocular-specific AEs were observed: endophthalmitis ( } n=1 \text {, severe; treated with } \\
\text { vitrectomy and intravitreal antibiotics); non-infectious inflammation ( } n=1 \text {, severe; treated with local } \\
\text { corticosteroids for several days); dehiscence of conjunctiva on the injection site ( } n=2 \text {, both mild; } \\
\text { treated with local antibiotic ointment for a few days). Vitreous opacities (bubbles) were anecdotally } \\
\text { reported and considered mild. Precise numbers were not tabulated." }\end{array}$ \\
\hline Siempsis $[32]$ & In terms of safety, there were no cases of endophthalmitis reported in our cohort during the study period \\
\hline Subhi $[33]$ & No safety assessment included \\
\hline Traine [34] & No safety assessment included \\
\hline
\end{tabular}

$A E$ adverse event

Table 4 Meta-regression analysis-impact of different variables on 2-year outcomes with IVT-AFL

\begin{tabular}{|c|c|c|c|c|c|}
\hline Variable & Intercept $(95 \% \mathrm{CI})$ & Random-effects estimate (95\% CI) & $I^{2}(\%)$ & $N$ & $\begin{array}{l}\text { Moderator } \\
R^{2}\end{array}$ \\
\hline Region & $6.39(1.57-11.21)$ & $\begin{array}{l}\text { Europe: }-2.30(-8.37 \text { to } 3.77) \\
\text { UK: }-2.54(-8.60 \text { to } 3.52)\end{array}$ & 71.50 & 9 & 0.11 \\
\hline Baseline BCVA & $-0.96(-30.49$ to 28.56$)$ & $0.09(-0.41$ to 0.60$)$ & 76.59 & 9 & 0.12 \\
\hline Baseline age & $22.16(-79.34$ to 123.65$)$ & $-0.22(-1.52$ to 1.09$)$ & 58.46 & 6 & 13.30 \\
\hline Baseline CRT & $14.44(-24.69$ to 53.56$)$ & $-0.03(-0.13$ to 0.08$)$ & 59.56 & 5 & 100.00 \\
\hline Injections (2 years) & $-3.58(-32.08$ to 24.92$)$ & $0.69(-1.54$ to 2.93$)$ & 52.78 & 6 & 10.19 \\
\hline Injections (1st year) & $-12.23(-97.51$ to 73.04$)$ & $2.24(-8.58$ to 13.07$)$ & 55.60 & 6 & 0.35 \\
\hline
\end{tabular}

CRT Central retinal thickness 
numerically positive association between 2-year outcomes with IVT-AFL and the number of injections administered in the first year (Table 4). However, this did not reach statistical significance.

\section{DISCUSSION}

This analysis aimed to review and summarize evidence from observational studies describing real-world 2-year outcomes with IVT-AFL in nAMD. The analysis summarized data from treatment-naïve patients with nAMD who initiated treatment with IVT-AFL between 2012 and 2016, providing an overview of clinical practice experience with IVT-AFL in different geographic locations and multiple populations.

The data identified in the literature review describe 2-year outcomes with IVT-AFL prior to the landmark ALTAIR study [35] and the inclusion of the T\&E posology in the IVT-AFL label, in which, after the three initial monthly doses, the 2-month injection interval can be increased by 2 - or 4 -week intervals to maintain stable visual and/or anatomic outcomes [36]. The analysis provides an overview of clinical practice and outcomes at a time when the initial IVTAFL label (three initial monthly doses followed by a fixed bimonthly regimen in the first year and variable regimen in the second year) was the primary treatment approach. The data identified did not allow for characterization of the impact associated with the implementation of the IVT-AFL T\&E label, whereby the 2-month injection interval can be increased by 2- or 4-week intervals to maintain stable visual and/ or anatomic outcomes.

Despite not having an approved T\&E posology in the label at the time (2012-2016), and despite the scarce evidence from randomized clinical trials describing the efficacy of T\&E regimens with IVT-AFL, the literature review identified real-world data describing 2-year outcomes in patients treated with IVT-AFL using flexible regimens and T\&E approaches $[25,26,29-31,34]$. The studies identified in the literature review do not reflect the current IVTAFL T\&E label [36], nor do they follow the learnings from the ALTAIR study [37], in which injection intervals were extended by 2 - or 4-week intervals.

Our analysis showed that, after 2 years, patients treated with IVT-AFL report significant gains in VA versus baseline. The pooled analysis (all studies) estimated a mean gain in VA versus baseline of +4.49 ETDRS letters for the combined population. The subanalysis of the studies describing patients treated using flexible T\&E regimens estimated a higher gain in VA versus baseline, with a mean gain of +5.91 ETDRS letters. Mean VA after 2 years was 62.55 ETDRS letters for the combined population, with $47.39 \%$ of the patients reporting a BCVA $\geq 70$ ETDRS letters. The results of the pooled analysis and the T\&E subanalysis provide additional evidence that a proactive treatment approach with IVT-AFL in clinical practice significantly improves a patient's visual acuity versus baseline.

The mean gain in VA registered in clinical practice for the combined population at 2 years was lower than the mean gain registered at Week 96 in the VIEW studies (+ 4.49 vs. +7.60 ETDRS letters in VIEW [5]), but the mean gain in VA for the T\&E group was of a similar magnitude to the outcomes registered in the VIEW trials (+ 5.91 vs. +7.60 ETDRS letters in VIEW [5]). Although the mean gains in VA observed in clinical practice are significant, there are differences versus the mean gains observed in randomized trials.

When reviewing the baseline characteristics of the real-world population and the clinical trial population, we observed that the realworld patients were older (78.62 vs. 75.80 years, respectively) and had a higher baseline VA (57.73 vs. 53.60 ETDRS letters, respectively). The analysis did not provide a pooled estimate for lesion type or size, but from studies, such as that of Barthelmes et al. [26], we know that some of the real-world populations reported significant differences in the size and type of lesions (59\% occult lesions in the real world vs. $37.6 \%$ in the clinical trial population). The analysis did not quantify how the different baseline characteristics impacted the mean VA gain in the real-world population and to what extent the older population, the higher baseline $\mathrm{VA}$, and the higher proportion of patients with 
occult lesions justify the lower mean gains in VA observed in clinical practice.

A previous meta-analysis has assessed 2-year real-world data with other anti-VEGF agents [30]. In a meta-analysis of ranibizumab realworld studies, Kim et al. [20] estimated a mean gain in VA after 1 and 2 years of treatment with ranibizumab. After 2 years of treatment with ranibizumab, the mean gain in VA ranged from +1.2 to +3.4 ETDRS letters for the overall population [30]. The mean gain estimated by Kim et al. [20] was lower than the mean gain estimated by the authors for patients treated with IVT-AFL $(+4.49$ ETDRS letters for the combined population). Patient baseline characteristics were similar in both studies (mean baseline age of 78.8 years and mean baseline VA of 53.6 ETDRS letters in the ranibizumab-treated patients) [20], but ranibizumab was primarily used following reactive treatment approaches such as PRN [20]. This contrasts with the IVTAFL studies that primarily report proactive treatment approaches $[27,33]$. The authors are not aware of any publication assessing the relative effectiveness of IVT-AFL versus ranibizumab at 2 years using real-world data. In that context, and to minimize any bias associated with naïve comparisons of different metaanalyses, we focus only on reporting the mean VA gains for the combined population and defer any conclusions on relative effectiveness for future research.

The evidence identified in the literature review indicates that it was possible to achieve good 2-year outcomes with IVT-AFL in clinical practice and to maintain the VA gains achieved during the first year of treatment in the second year [24, 26, 28, 30-34]. This was achieved by moving from the proactive bimonthly regimen to a variable dosing regimen and with a significant reduction in the number of IVT-AFL injections in Year 2 [24, 26, 28, 30-34]. A published meta-analysis of real-world outcomes with IVT-AFL estimated mean VA gains after 1 year at between +5.97 ETDRS letters [13] and +5.30 ETDRS letters [15]. Our analysis estimated a mean gain after 2 years of +4.49 ETDRS letters. A naïve comparison of the 1-year and 2-year meta-analyses suggests that the outcomes achieved during the first year with IVT-AFL are sustained over the second year.

A mean injection frequency of 12.34 injections over 2 years calculated in this study is consistent with the initial IVT-AFL label (3 initial monthly doses followed by a fixed bimonthly regimen in the first year and a variable regimen in the second year), and in line with what was reported in the VIEW 96-week assessment (11.2 injections) [7]. When assessing the differences in injection frequency, it is important to take into consideration that the VIEW studies reported the mean number of injections at 96 weeks [7], whereas the observational studies reported the mean number of injections at 2 years (104 weeks). The analysis of the individual studies confirms that the injection frequency decreased from Year 1 (between 7.2 injections [28] and 8.4 injections [31]) to Year 2 (between 2.5 injections and 6.1 injections [31]) in patients treated following the initial label or the early T\&E regimens. When compared with the combined population, patients treated with $T \& E$ regimens reported a higher mean injection frequency of 13.59 injections over 2 years. The higher number of injections could be driven by how T\&E was defined and implemented. Most studies defined similar anatomic criteria for extending the interval (absence of intraretinal fluid or absence of both intraretinal and subretinal fluid) but took different approaches to the initial monthly doses and the extension. Two of the studies used a T\&E approach similar to the current label $[29,34]$, administering the three monthly initial doses and extending the injection interval by 2 weeks to a maximum of 14 weeks, with patients receiving (on average) 11.1 and 10.5 injections, respectively. In other studies, the injection interval was extended by 2 weeks, but the maximum injection interval was limited to 12 weeks, with patients receiving an average of 13.8 injections [30]. A study that reported a higher mean number of injections, 14.5 injections over 2 years [31], considered an approach whereby patients received monthly injections until the macula became dry, and afterwards the injection interval was extended by 2 weeks up to a maximum of 14 weeks. In the ALTAIR study [35], after the three consecutive monthly 
doses, the injection intervals were extended by 2 and 4 weeks to a maximum of 16 weeks, reducing the mean number of injections to 10.5 over 2 years. Further research is warranted to determine the outcomes associated with the implementation of an ALTAIR-like [35] approach in clinical practice and the impact associated with the new T\&E label.

Few studies reported 2-year safety data: Barthelmes et al. [26] reported ten adverse events after administering 2415 injections; Matsumoto et al. [30] reported no severe adverse events; Mekjavić et al. [31] reported four ocular-specific adverse events (endophthalmitis, non-infection inflammation, and dehiscence of conjunctiva on the injection site); and Siempsis et al. [32] did not report any cases of endophthalmitis. The qualitative assessment of the conclusions provided by the authors of the individual studies suggests that there were no new safety signals identified during the studies and very few adverse events were reported; however, the data reported did not allow us to complete a formal meta-analysis and to provide a pooled estimate of the 2-year safety associated with the use of IVT-AF. The absence of comprehensive reporting of adverse events is a limitation and should be considered in future research.

The analysis identified a high heterogeneity $\left(I^{2}\right)$ that is indicative of high between-study variation. In this situation, it is recommended to focus on the random-effects estimate rather than the fixed-effects estimate [37]. Both estimates are reported for completeness, but in the Results section of this article, only the randomeffects estimate is described. The aim of the meta-regression analysis was to identify how key variables, such as patient baseline characteristics (age, baseline BCVA, and CRT) and injection frequency, are associated with 2-year outcomes with IVT-AFL. However, there were limited data to conduct these analyses (due to a limited number of studies and data reported). Further research is warranted to confirm or refute the results of the meta-regression.

There are limitations associated with this analysis. The literature review was conducted with the MEDLINE ${ }^{\circledR}$ database using ProQuest and did not include other data sources. Although MEDLINE $^{\circledR}$ has extensive coverage and is commonly used, not including other databases is a limitation of the analysis. The literature search was conducted in July 2019 and may not capture more recent publications describing 2-year outcomes with IVT-AFL. The data used originate primarily from retrospective studies that have an associated bias and are associated with increased imprecision, incomplete follow-up, and recall bias [38, 39]. There was an attempt to reduce publication bias [40] and uncertainty associated with small sample sizes [41] by excluding studies that reported $<40$ patients/eyes from the meta-analysis. The choice to set the cutoff at 40 patients was arbitrary and defined by the authors, as there is no formal reference that can be used to define what constitutes a "small sample size" study. Another limitation of this analysis is that only 11 studies were identified, which is low for assessing interstudy differences in a meta-analysis. It should be considered that this low number of studies was the result of strict selection criteria that aimed to reduce bias that is traditionally associated with meta-analyses using real-world research (e.g., imprecision, publication bias, etc.). Furthermore, the analysis was based on aggregate (mean) data and not patient-level data, which are not free from ecological bias.

\section{CONCLUSION}

Patients treated with IVT-AFL reported significant 2-year gains in VA versus baseline. The evidence indicates that the visual gains achieved during the first year of treatment are maintained through the second year. This outcome was achieved with a significant reduction in the mean number of IVT-AFL injections administered in Year 2 of treatment.

\section{ACKNOWLEDGEMENTS}

Funding. This research was funded by Bayer Consumer Care AG, Basel, Switzerland. Bayer Consumer Care AG is also responsible for funding the journal's Rapid Service and Open Access Fees. 
Authorship. All named authors meet the International Committee of Medical Journal Editors (ICMJE) criteria for authorship for this article, take responsibility for the integrity of the work as a whole, and have given their approval for this version to be published.

Author Contributions. Joao Carrasco developed the hypothesis and overall concept. Joao Carrasco, Jisu Yoon, and Jelle Spoorendonk contributed to the data collection and analysis. Vincent Daien and Bora Eldem contributed to the review and assessment of the clinical data used in the analysis. All authors were involved in the analysis, interpretation of the results, and the review and development of the manuscript. All authors have provided final approval of the manuscript to be published and agree to be accountable for all aspects of the work by ensuring that questions related to the accuracy or integrity of any part of the work are appropriately investigated and resolved.

Medical Writing, Editorial, and Other Assistance. Editorial support was provided by ApotheCom (London, UK) and was funded by Bayer Consumer Care AG, Pharmaceuticals, Switzerland.

Disclosures. Joao Carrasco is a paid employee of Bayer Consumer Care AG, Basel, Switzerland. Vincent Daien reports consulting fees, travel support, and financial and non-financial support outside the submitted work from Alcon, Bayer, Horus, Novartis, and Thea. Bora Eldem reports consulting fees, travel support, and financial and non-financial support outside the submitted work from Alcon, Allergan, Novartis, Bayer, Bausch \& Lomb, Ophthotech, Pfizer, Roche, Sanofi, Santen, Servier, and Thea. Jelle Spoorendonk is a paid employee of Pharmerit International, an OPEN Health Company, which was contracted by Bayer to assist in the analysis. Jisu Yoon was a paid employee of Pharmerit International, an OPEN Health Company, at the time that this study was completed and was contracted by Bayer to assist in the analysis. The authors thank Walter Bouwmeester from Pharmerit International, an
OPEN Health Company, for his contribution to the literature review and meta-analysis.

Compliance with Ethics Guidelines. This article is based on previously conducted studies and does not contain any studies with human participants or animals performed by any of the authors.

Data Availability. All data generated or analyzed during this study are included in this published article or as supplementary information files.

Open Access. This article is licensed under a Creative Commons Attribution-NonCommercial 4.0 International License, which permits any non-commercial use, sharing, adaptation, distribution and reproduction in any medium or format, as long as you give appropriate credit to the original author(s) and the source, provide a link to the Creative Commons licence, and indicate if changes were made. The images or other third party material in this article are included in the article's Creative Commons licence, unless indicated otherwise in a credit line to the material. If material is not included in the article's Creative Commons licence and your intended use is not permitted by statutory regulation or exceeds the permitted use, you will need to obtain permission directly from the copyright holder. To view a copy of this licence, visit http://creativecommons.org/licenses/bync/4.0/.

\section{REFERENCES}

1. Flaxman SR, Bourne RRA, Resnikoff S, et al. Global causes of blindness and distance vision impairment 1990-2020: a systematic review and meta-analysis. Lancet Glob Health. 2017;5:e1221-34.

2. Ferris FL 3rd, Fine SL, Hyman L, Vision Loss Expert Group of the Global Burdenof Disease Study. Agerelated macular degeneration and blindness due to neovascular maculopathy. Arch Ophthalmol. 1984;102:1640-2.

3. Brown DM, Kaiser PK, Michels M, ANCHOR Study Group, et al. Ranibizumab versus verteporfin for 
neovascular age-related macular degeneration. N Engl J Med. 2006;355:1432-44.

4. Rosenfeld PJ, Brown DM, Heier JS, MARINA Study Group, et al. Ranibizumab for neovascular age-related macular degeneration. $\mathrm{N}$ Engl J Med. 2006;355:1419-31.

5. Heier JS, Brown DM, Chong V, VIEW 1 and VIEW 2 Study Groups, et al. Intravitreal aflibercept (VEGF trap-eye) in wet age-related macular degeneration. Ophthalmology. 2012;119:2537-48.

6. Schmidt-Erfurth U, Kaiser PK, Korobelnik JF, et al. Intravitreal aflibercept injection for neovascular age-related macular degeneration: ninety-six-week results of the VIEW studies. Ophthalmology. 2014;121:193-201.

7. Daien V, Finger RP, Talks JS, et al. Evolution of the treatment paradigms in neovascular age-related macular degeneration: a review of real-world evidence. Br J Ophthalmol. 2020. https://doi.org/10. 1136/bjophthalmol-2020-317434.

8. Talks JS, Lotery AJ, Ghanchi F, United Kingdom Aflibercept Users Group, et al. First-year visual acuity outcomes of providing aflibercept according to the VIEW study protocol for age-related macular degeneration. Ophthalmology. 2016;123:337-43.

9. Framme C, Eter N, Hamacher T, et al. Aflibercept for patients with neovascular age-related macular degeneration in routine clinical practice in Germany: twelve-month outcomes of PERSEUS. Ophthalmol Retina. 2018;2:539-49.

10. Lee AY, Lee CS, Egan CA, et al. UK AMD/DR EMR REPORT IX: comparative effectiveness of predominantly as needed (PRN) ranibizumab versus continuous aflibercept in UK clinical practice. $\mathrm{Br} \mathrm{J}$ Ophthalmol. 2017;101:1683-8.

11. Weber M, Velasque L, Coscas F, RAINBOW Study Investigators, et al. Effectiveness and safety of intravitreal aflibercept in patients with wet age-related macular degeneration treated in routine clinical practices across France: 12-month outcomes of the RAINBOW study. BMJ Open Ophthalmol. 2019;4:e000109.

12. Almuhtaseb H, Kanavati S, Rufai SR, Lotery AJ. Oneyear real-world outcomes in patients receiving fixed-dosing aflibercept for neovascular age-related macular degeneration. Eye (London). 2017;31: 878-83.

13. Guo MY, Cheng J, Etminan M, Zafari Z, Maberley D. One year effectiveness study of intravitreal aflibercept in neovascular age-related macular degeneration: a meta-analysis. Acta Ophthalmol. 2019;97: e1-7.
14. Zhang $\mathrm{Y}$, Chioreso $\mathrm{C}$, Schweizer ML, Abràmoff MD. Effects of aflibercept for neovascular age-related macular degeneration: a systematic review and meta-analysis of observational comparative studies. Invest Ophthalmol Vis Sci. 2017;58:5616-27.

15. Carrasco J, Pietsch GA, Nicolas MP, Koerber C, Bennison C, Yoon J. Real-world effectiveness and real-world cost-effectiveness of intravitreal aflibercept and intravitreal ranibizumab in neovascular age-related macular degeneration: systematic review and meta-analysis of real-world studies. Adv Ther. 2020;37:300-15.

16. Eleftheriadou M, Vazquez-Alfageme C, Citu CM, et al. Long-term outcomes of aflibercept treatment for neovascular age-related macular degeneration in a clinical setting. Am J Ophthalmol. 2017;174: $160-8$.

17. Centre for Reviews and Dissemination. Systematic reviews: CRD's guidance for undertaking reviews in health care. York: University of York; 2006.

18. Moher D, Liberati A, Tetzlaff J, Altman DG, PRISMA Group. Preferred reporting items for systematic reviews and meta-analyses: the PRISMA statement. J Clin Epidemiol. 2009;62:1006-12.

19. Stroup DF, Berlin JA, Morton SC, et al. Meta-analysis of observational studies in epidemiology: a proposal for reporting. Meta-analysis of Observational Studies in Epidemiology (MOOSE) group. JAMA. 2000;283:2008-12.

20. Kim LN, Mehta H, Barthelmes D, Nguyen V, Gillies MC. Meta-analysis of real-world outcomes of intravitreal ranibizumab for the treatment of neovascular age-related macular degeneration. Retina. 2016;36:1418-31.

21. Buuren SV, Groothuis-Oudshoorn K. mice: multivariate imputation by chained equations in R. J Stat Softw. 2011;45:1-67.

22. Higgins JP, Thompson SG. Quantifying heterogeneity in a meta-analysis. Stat Med. 2002;21: 1539-58.

23. Viechtbauer W. Conducting meta-analyses in $\mathrm{R}$ with the metafor package. J Stat Softw. 2010;36: $1-48$.

24. Almuhtaseb H, Johnston RL, Talks JS, Lotery AJ. Second-year visual acuity outcomes of nAMD patients treated with aflibercept: data analysis from the UK Aflibercept Users Group. Eye. 2017;31: 1582-8.

25. Augsburger M, Sarra GM, Imesch P. Treat and extend versus pro re nata regimens of ranibizumab and aflibercept in neovascular age-related macular 
degeneration: a comparative study. Graefes Arch Clin Exp Ophthalmol. 2019;257:1889-95.

26. Barthelmes D, Nguyen V, Daien V, Fight Retinal Blindness Study Group, et al. Two year outcomes of "treat and extend" intravitreal therapy using aflibercept preferentially for neovascular age-related macular degeneration. Retina. 2018;38:20-8.

27. Chatziralli I, Regan SO, Mohamed R, Talks J, Sivaprasad S, UK Aflibercept Users Group. Intravitreal aflibercept for neovascular age-related macular degeneration in patients aged 90 years or older: 2-year visual acuity outcomes. Eye. 2018;32:1523-9.

28. Eleftheriadou M, Gemenetzi M, Lukic $\mathrm{M}$, et al. Three-year outcomes of aflibercept treatment for neovascular age-related macular degeneration: evidence from a clinical setting. Ophthalmol Ther. 2018;7:361-8.

29. Garweg JG, Gerhardt C, Kodjikian L, Pfister IB. Reallife experience with aflibercept and ranibizumab in the treatment of newly diagnosed neovascular agerelated macular degeneration over 24 months. J Ocul Pharmacol Ther. 2017;33:567-72.

30. Matsumoto $\mathrm{H}$, Morimoto $\mathrm{M}$, Miura $\mathrm{K}$, Ito $\mathrm{A}$, Akiyama $H$. Treat-and-extend regimen with aflibercept for neovascular age-related macular degeneration. Ophthalmol Retina. 2018;2:462-8.

31. Mekjavić PJ, Gregorčič B, Oberč C, Podgoršek S. Treat-and-extend therapy using intravitreal aflibercept for neovascular age-related macular degeneration: 2-year real-world practice data from Slovenia. BMC Ophthalmol. 2018;18:333.

32. Siempis T, El Abiary M, Patel R, Gupta M. Twentyfour-month real-world visual outcomes of intravitreal aflibercept as monotherapy for the treatment of neovascular age-related macular degeneration. Oman J Ophthalmol. 2019;12:99-103.
33. Subhi Y, Sørensen TL. Neovascular age-related macular degeneration in the very old ( $\geq 90$ years): epidemiology, adherence to treatment, and comparison of efficacy. J Ophthalmol. 2017;7194927.

34. Traine PG, Pfister IB, Zandi S, Spindler J, Garweg JG. Long-term outcome of intravitreal aflibercept treatment for neovascular age-related macular degeneration using a "treat-and-extend" regimen. Ophthalmol Retina. 2019;3:393-9.

35. Ohji M, Takahashi K, Okada AA, Kobayashi M, Matsuda Y, Terano Y, ALTAIR Investigators. Efficacy and safety of intravitreal aflibercept treat-and-extend regimens in exudative age-related macular degeneration: 52- and 96-Week findings from ALTAIR: a randomized controlled trial. Adv Ther. 2020;37:1173-87.

36. European Medicines Agency. Aflibercept summary of product characteristics. https://www.ema.europa. eu/en/documents/product-information/eylea-eparproduct-information_en.pdf. Accessed 11 Nov 2020.

37. Riley RD, Higgins JPT, Deeks JJ. Interpretation of random effects meta-analyses. BMJ. 2011;342:d549.

38. Balshem $\mathrm{H}$, Helfand $\mathrm{M}$, Schünemann $\mathrm{HJ}$, et al. GRADE guidelines: 3 . Rating the quality of evidence. J Clin Epidemiol. 2011;64:401-6.

39. Guyatt GH, Oxman AD, Vist G, et al. GRADE guidelines: 4. Rating the quality of evidence-study limitations (risk of bias). J Clin Epidemiol. 2011;64: 407-15.

40. Sedgwick P. What is publication bias in a metaanalysis? BMJ. 2015;351:h4419.

41. Turner RM, Bird SM, Higgins JP. The impact of study size on meta-analyses: examination of underpowered studies in Cochrane reviews. PLoS ONE. 2013;8:e59202. 